\title{
Follicular Thyroid Carcinoma Presenting as a Palpable Head Mass: A Case Report
}

\author{
Andrew L. Atkinson ${ }^{a} \quad$ Andrew Rosenthal ${ }^{b}$ \\ Dawn Nardielloc

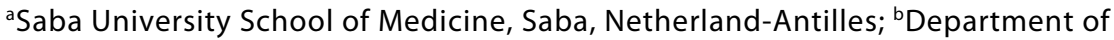 \\ Trauma Surgery, Memorial Regional Hospital and 'Memorial Regional Hospital, \\ Hollywood, Fla., USA
}

\section{Key Words}

Follicular thyroid cancer - Skull metastasis - Head mass - Thyroid carcinoma metastasis . Radiation therapy

\section{Abstract}

This case report touches on a young, 35-year-old patient with a highly unusual presentation of a palpable left parietal skull mass that was found to be metastatic follicular thyroid carcinoma.

\section{Introduction}

An otherwise healthy 35-year-old Haitian female presented to the surgery clinic with a palpable head mass in the region of the left parietal skull that was approximately $5 \mathrm{~cm}$ in length. The patient had been followed by an endocrinologist for the past two years for the reason that a thyroid isthmus mass as well as a left-sided lobular mass had been found on ultrasound. She had had two thyroid fine needle aspirations up to that point and they were both negative for malignancy.

After excisional biopsy of the skull mass, a specimen was sent to pathology; histologically revealing a 'predominate macrofollicular architecture', consistent with metastatic carcinoma. This case report illustrates the very rare occurrence of metastatic follicular thyroid carcinoma in the skull in this particular patient and the management thereafter. 


\begin{tabular}{|c|c|c|c|}
\hline $\begin{array}{l}\text { Cose Reports in } \\
\text { Ona.ayly }\end{array}$ & $\begin{array}{l}\text { Case Rep Oncol 2010;3:106-109 } \\
\text { D0I: } 10.1159 / 000312708\end{array}$ & Published online: April 23, 2010 & $\begin{array}{l}\text { @ } 2010 \text { S. Karger AG, Basel } \\
\text { ISSN 1662-6575 } \\
\text { www.karger.com/cro }\end{array}$ \\
\hline
\end{tabular}

\section{Case Presentation}

A 35-year-old female patient presented to the outpatient surgery clinic with the chief complaint of a nontender, very slowly growing mass on the left side of her head. A magnetic resonance imaging (MRI) study was ordered and revealed the initial lesion that was in the region of the left parietal bone, approximately measuring $4.6 \mathrm{~cm} \times 3.5 \mathrm{~cm} \times 3 \mathrm{~cm}$ (fig. 1 ). The mass itself extended inferiorly into the intracranial epidural space. Subsequently, the recommendation was to remove the lesion and to send a tissue sample to pathology to see exactly what type of tissue the mass was made up of.

The patient was taken to the operating room, and prepped in regular fashion while her head was fixed in a Mayfield head holder in neutral position. The lesion was dissected away from the scalp and a selfretaining retractor was placed. The bony edges around the lesion appeared to be partially destroyed by the mass circumferentially. The lesion was removed with a pituitary rongeur and bipolar cautery from the dura. The mass was hemorrhagic; bleeding was controlled with bipolar cautery. Irregular bony edges were removed piecemeal with a Leksell rongeur circumferentially. After bleeding was controlled with bone wax and DuraSeal, the wound was irrigated thoroughly. A titanium mesh was then placed at the site of the defect and anchored with 3.5-mm Lorenz screws. The patient tolerated the procedure well and was then taken to recovery.

The pathology report came back a few days later revealing thyroid carcinoma, follicular type. After a few weeks of recovery from the initial surgery of the skull mass, she was then referred for a total thyroidectomy.

Her past medical history was only remarkable for the two masses found on ultrasound two years earlier. Fine needle aspirations were done on both masses as well as core needle biopsies which suggested benign pathology. The isthmus mass measured approximately $1.5 \mathrm{~cm} \times 1.5 \mathrm{~cm}$, while the left sided thyroid mass measured $3 \mathrm{~cm} \times 4 \mathrm{~cm}$. There was a negative family history for thyroid carcinoma, and the patient denied ever having been exposed to radiation or having any other remarkable risk factors. The patient was currently taking no medications and had a negative social history. The rationale behind doing a total thyroidectomy was explained to the patient and the patient was then scheduled for surgery.

The patient was taken to the operating room, prepped in regular fashion and endotracheally intubated. The thyroid was excised en bloc along with the large isthmus tumor fully intact. During the procedure, moderate lymphadenopathy was witnessed, five to six lymph nodes were also resected and sent to pathology.

Besides issues with hypocalcemia, the patient had a relatively unremarkable recovery. The patient was discharged and told to follow-up for radiation iodine treatment and external beam radiation to the scalp. A Hong Kong study in 2002 demonstrated that when there is residual disease after thryoidectomy, external beam radiation doubles local regional control [1]. This study is strongly relevant for our patient for the reason that in the initial surgery when the lesion was resected off the skull, the margin status was indeterminate/ill-defined; even though fragments of the skull were also excised, there really is no way to be completely positive that all cancer was removed with surgery.

Written informed consent was obtained from the patient to publish this case report.

\section{Discussion}

Follicular carcinoma is the second most prevalent of the thyroid carcinomas with an incidence of approximately 10-15\%. Follicular carcinoma spreads hematogenously and favors the lungs and bones, in which the carcinoma is osteolytic in nature. In less than $10 \%$ of cases found with follicular carcinoma, there is evidence of lymphatic involvement [2]. The patient presentation above is highly unusual because of the fact that this patient was being followed by an endocrinologist who aggressively worked up the patient for two benign lesions of the thyroid over a two-year period, but still managed to have significant metastasis in the left parietal region of the skull that measured almost $5 \mathrm{~cm}$ in length. The location of the metastasis in the skull itself is very rare and has only been documented in medical literature a few times. The bones most often involved in metastasis of follicular carcinoma are the long bones, such as the femur and flat bones, particularly the pelvis and 


\begin{tabular}{c|l|l|l}
$\begin{array}{c}\text { Cose Reports in } \\
\text { Ondity }\end{array}$ & $\begin{array}{l}\text { Case Rep Oncol 2010;3:106-109 } \\
\text { D0I: } 10.1159 / 000312708\end{array}$ & Published online: April 23, 2010 & $\begin{array}{l}\text { @ 2010 S. Karger AG, Basel } \\
\text { ISSN 1662-6575 } \\
\text { www.karger.com/cro }\end{array}$ \\
\hline
\end{tabular}

sternum [3]. It is not unusual for a pathological break of a long bone to be the first clinically significant manifestation of follicular thyroid carcinoma.

The staging of follicular thyroid carcinoma is differentiated from the standpoint of the age of the patient. There are two categories: older than 45 years of age and younger than 45 years of age. Staging of patients who are younger than 45 years of age is quite simple; if the carcinoma is confined to only the thyroid with no lymph node involvement or metastasis, it is stage I. In our patient, who had distant metastasis, the carcinoma would be considered stage II, and there are subsequently only two stages for those under the age of 45. This method of staging is the tumor, node, metastasis method (TNM method) and is the official method of staging adopted by the American Joint Commission on Cancer. In cases of metastatic disease to lung and/or bone, adverse prognostic factors are said to include multiplicity of sites, older patient age at the time of discovery of the metastases, and absence of radioactive iodine uptake by the metastases [4]. In one series (which also included some 'moderately differentiated' types and probably some widely invasive tumors), the overall survival rates were $53 \%$ at 5 years, $38 \%$ at 10 years, and $30 \%$ at 15 years [5].

Fig. 1. MRI showing metastatic follicular thyroid carcinoma of the left parietal region of the skull. The mass itself invades as deep as the epidural space.

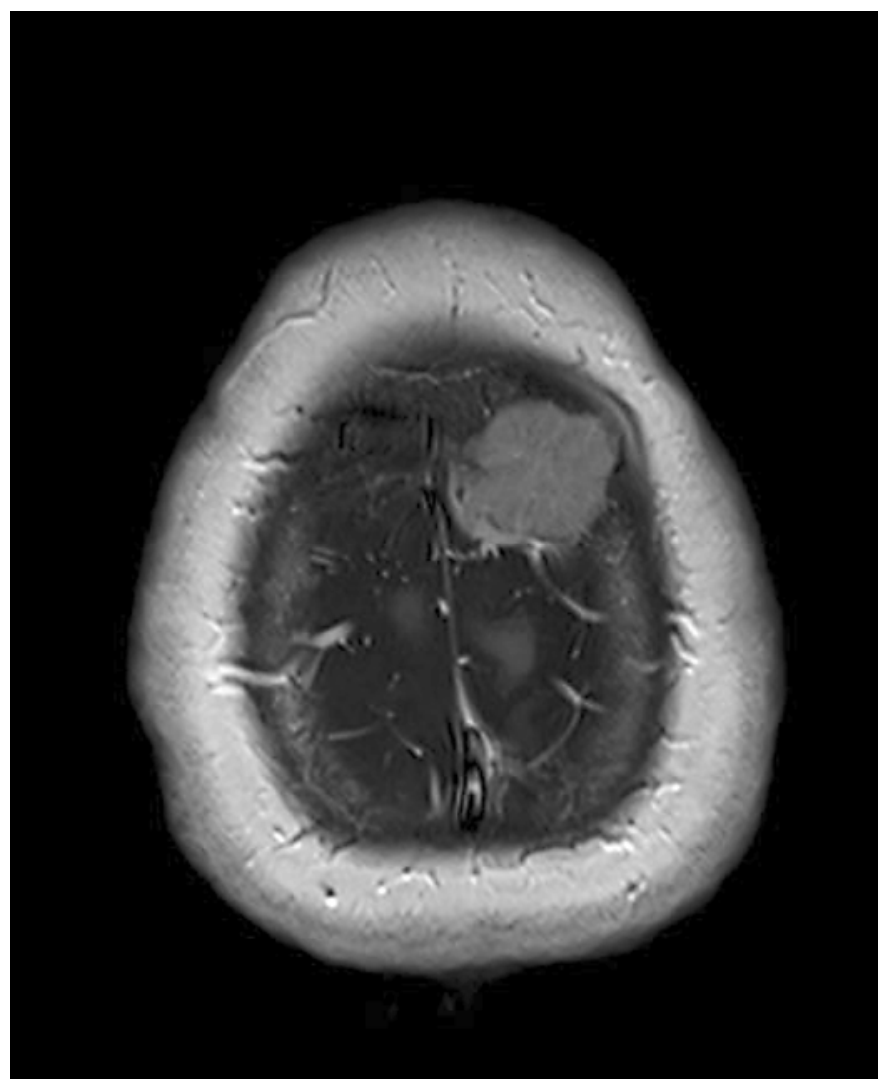




\section{References}

1 Chow SM, Law SC, Mendenhall WM, et al: Papillary thyroid carcinoma: prognostic factors and the role of radioiodine and external radiotherapy. Int $\mathrm{J}$ Radiat Oncol Biol Phys 2002;52:784-795.

2 Santacroce L, Gagliardi S: Thyroid, follicular carcinoma. Emedicine. 25 Sep 2009. Available at http://emedicine.medscape.com/article/278488-overview (accessed March 30, 2010).

-3 Nagamine Y, Suzuki J, Katakura R, Yoshimoto T, Matoba N, Takaya K: Skull metastasis of thyroid carcinoma. Study of 12 cases. J Neurosurg 1985;63:526-531.

4 Rosai J, Carcangui ML, Delellis RA: Armed Forces Institute of Patholgy; Atlas of Tumor Pathology. Third Series, Fascicle 5. Available at http://www.pathologyresources.com/AFIP/thyroid/tumor04.htm (accessed March 29, 2010).

5 Schlumberger M, Tubiana M, De Vathaire F, et al: Long-term results of treatment of 283 patients with lung and bone metastases from differentiated thyroid carcinoma. J Clin Endocrinol Metab 1986;63:960-967. 